\title{
Research Paper: Increasing Prevalence of Methamphetamine Use Among Women: Implication in Suicide Attempt
}

Omid Massah ${ }^{1}$ (D), Nastaran Rafiee ${ }^{2}$ (D), Ali Farhoudian ${ }^{133}$ (D), Bahman Bahmani ${ }^{4}$ (D), Elaheh Ahounbar ${ }^{1}$ (D), Seyed Hadi Mousavi ${ }^{* *}$ (D), Mohsen Roshani ${ }^{1}$ (D)

1. Substance Abuse and Dependence Research Center, University of Social Welfare and Rehabilitation Sciences, Tehran, Iran.

2. Department of General Psychology, Faculty of Psychology and Educational Sciences, Allameh Tabataba'i University, Tehran, Iran.

3. Department of Psychiatry, School of Medicine, Tehran University of Medical Sciences, Tehran, Iran.

4. Department of Counseling, University of Social Welfare and Rehabilitation Sciences, Tehran, Iran.

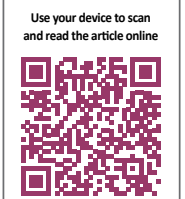

Citation: Massah O, Rafiee N, Farhoudian A, Bahmani B, Ahounbar E, Mousavi SH, et al. Increasing Prevalence of Methamphetamine Use Among Women: Implication in Suicide Attempt. Iranian Rehabilitation Journal. 2019; 17(1):61-66. http:// dx.doi.org/10.32598/irj.17.1.61

dol http://dx.doi.org/10.32598/irj.17.1.61

\section{(c) (1) (8)}

Article info:

Received: 19 Jul 2018

Accepted: 28 Dec 2018

Available Online: 01 Mar 2019

\section{Keywords:}

Methamphetamine, Opium,

Suicide attempt, Women, Iran

\section{ABSTRACT}

Objectives: This study aimed to compare the ratio of suicide attempts between female opium and Methamphetamine (MA) users to determine the relationship between the increased prevalence of MA and suicide risk.

Methods: In this cross-sectional study, 136 drug dependent females were randomly selected from Tehran. Data gathering was performed by a demographic questionnaire and Beck Scale for Suicidal Ideation. Data were analyzed by Chi-squared test and Independent Samples t-test.

Results: There was no significant different in suicidal ideation between the two groups; however, the suicide attempt was significantly higher in the MA users compared to opium users $(\mathrm{P}<0.001)$.

Discussion: Suicide attempt is much higher in females who use crystal MA, compared to female opium users. This could be a warning to prevent associated risks.

\section{Highlights}

- The probability of suicide attempt among women is increased due to methamphetamine use.

\section{Plain Language Summary}

All family members of a crystal meth user who lives with the family need to know that the possibility of a suicide attempt may increase in them. So, they must be careful to make it harder to do. They must get things that may be used for suicide away from the patient and be prepared for relief efforts. 


\section{Introduction}

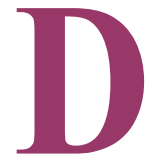

rug use disorder is a major health concern globally. According to the world drug report of 2017 , about $5 \%$ of the world's adult population have consumed drugs at least once in 2015 and $0.6 \%$ of the world total adult population suffered from drug use disorders [1]. Same values were calculated equal to $8.3 \%$ and $2.4 \%$, in Iran, respectively $[2,3]$.

In recent years, the rate of drug consumption has increased more rapidly in women than men around the world [1]. A similar trend has also been reported in Iran; the ratio of male to female drug consumers has decreased from 19 in 2007 to 11 in 2011. This ratio was much lower -about 8\%- for Methamphetamine (MA) abuse [4] which reflects increased use of MA among women [5]. Suicide attempt was estimated 17-43\% among people with drug use disorders [6-8] which is much higher than the general population (less than 3\%) [9]. Mood disorders such as depression and anxiety are recognized as critical risk factors for suicide attempt among women with drug use disorders [8]. In addition, psychotic symptoms, anxiety, depression and suicide are prevalent among MA dependents [10].

In Iran, there is a high incidence of depression and anxiety among MA dependent females [11] which can be a potential suicide risk among them and requires appropriate evaluation and attention. To our knowledge, no previous research has investigated the suicide attempt among female MA users in Iran. On the other hand, opium is the most prevalently used drug in Iran (in both males and females) [2-4]. Therefore, this study aimed to compare the ratio of suicide attempts between female opium and MA users to determine the relationship between the increased prevalence of MA abuse and suicide risk.

\section{Methods}

This study was part of a larger cross-sectional survey on women with drug use disorders in Tehran City, Iran (2015).

\section{Study participants}

One hundred forty women with drug use disorders participated in this study. One hundred twenty of them were selected from outpatient treatment centers for substance use, a self-help Non-Governmental Organization $(\mathrm{NGO})^{1}$ group, short term residential treatment centers,

1. Congress 60 is a non-government organization and self-help group working in the field of treatment and rehabilitation of drug dependents harm-reduction centers (DIC) $)^{2}$, imprisoned women, and those under compulsory treatment (clause 16$)^{3}$ by simple random sampling method. Moreover, 20 female drug users under no treatment were selected by snowball sampling method. Twenty participants were selected from each 7 mentioned sub-groups. Inclusion criteria were opium or MA use and being diagnosed with drug dependence based on Diagnostic and Statistical Manual of Mental Disorders, $5^{\text {th }}$ Edition: DSM-5 (DSM-V). Exclusion criteria were poly-drug use, psychosis or any psychiatric condition affecting the participant's responses.

\section{Measurements}

Survey data were collected by a researcher-made data gathering form. A pilot study was conducted to evaluate the validity and reliability of the tool, and Kaiser-MeyerOlkin (KMO) and Cronbach's alpha of 0.722 and 0.726 were obtained, respectively. Additionally, Beck Scale for Suicidal Ideation (BSSI) was used to investigate suicidal ideation [12].

Its concurrent validity with Beck Depression Inventory (BDI) has been reported as $76 \%$ and its reliability was calculated as $95 \%$ by Cronbach's alpha [13]. After the completion of data gathering, 136 questionnaires were recognized eligible for statistical analysis.

\section{Data analysis}

The obtained data have been analyzed by descriptive and inferential statistics using SPSS. Mean \pm SD have been used to describe the achieved data. Independent Samples t-test was used to compare the BSSI results between the two groups and the Chi-squared test was used to compare nonparametric variables.

\section{Results}

The Mean \pm SD age of opium and MA users were $36 \pm 10$ and $31 \pm 7$ years, respectively. Findings suggested no statistically significant difference between the two groups of study, in respect of their level of education $(\mathrm{P}=0.664)$, ethnicity $(\mathrm{P}=0.822)$, family monthly income $(\mathrm{P}=0.119)$, type of occupation in the past year $(\mathrm{P}=0.524)$, parent's level of education $(\mathrm{P}=0.632)$, parent's occupation $(\mathrm{P}=0.588)$, and housing status $(\mathrm{P}=0.464)$. In conclusion, there was no significant difference in demographic, socio-economic, and cultural variables between the two groups of study.

2. Drop -In- Center

3. The law that obliges drug dependents to undergo compulsory treatment 
Table 1. Comparing suicide attempt between female opium and MA users in Tehran (Chi-Squared test)

\begin{tabular}{|c|c|c|c|}
\hline \multirow{2}{*}{ Group } & \multicolumn{2}{|c|}{ History of Serious Suicide Attempt (\%) } & \multirow{2}{*}{$\mathbf{P}$} \\
\hline & Yes & No & \\
\hline Opium users & $5(9.25)$ & 49(90.75) & \\
\hline MA users & $34(41.46)$ & $48(58.54)$ & $<0.001$ \\
\hline
\end{tabular}

Iranian Rehabilitation Journal

The Mean \pm SD total score of BSSI among opium users $(n=54)$ were $29.6 \pm 6.2$ which fell in the range of 6 to 34 and these values for MA users $(n=82)$ were $27.8 \pm 7.5$ (range $=5-33$ ). There was no significant difference in suicidal ideation between the two groups $(\mathrm{P}=0.825)$. Two groups of study were compared in respect of their suicide attempt. As per Table 1, suicide attempt was significantly higher in MA users than opium users $(\mathrm{P}<0.001)$.

\section{Discussion}

This research compared suicide attempt between female MA (glass or crystal MA) users and female opium users in Tehran City, Iran. Considering the increasing MA use among women [5], unfamiliar complications are expected in this population. According to the obtained data, the rate of suicide attempt was higher in crystal MA users. Self-injury behaviors aiming to end one's own life are considered as suicidal behavior. A complicated condition of current psychiatric disorders along with stress may lead to suicide which is associated with numerous affecting factors, including childhood experiences, impulsivity, pessimism, familial/ genetic factors, and aggression [14].

There were differences between the two groups of study in terms of personality traits, cognitive issues and complications associated with the use of each substance. Impairments in cognitive-emotional processing are prevalent in drug use disorders. This is because chronic substance use may lead to long-term degeneration in the brain and impairment in its functions [15]. Dopamine release in reinforcing normative behaviors leads to behavioral activation and behavioral responses to instinctual human needs [16]. Moreover, substance abuse evokes dopamine release in dopaminergic pathways. MA use is associated with higher dopamine release, in comparison with opium [17].

MA users suffer from widespread deficits in neurocognitive skills, as a result of alternations in the neurotransmitter system, especially at dopamine terminals. Such alternations lead to impairments in cognitive, emotional, and behavioral functions $[18,19]$. In addition, cognitive defects in MA users seem to be greater than that of the opium users [20]. Furthermore,cognitive deficits were associated with suicidal behavior [21, 22]; thus, we can expect higher odds of suicide attempt among crystal meth users, compared to opium users.

Some personality traits can well distinguish between substance users and their tendency toward a specific substance [23, 24]. Moreover, prior research reported a correlation between personality disorders and the type of abused substance [23, 25]. Interestingly, there is an association between the data suggested by such investigations and studies on personality disorders and suicide attempt, which suggests the odds of a higher incidence of suicide, consequent to the use of some types of drugs.

Previous investigations highlighted the role of sensation seeking in tendency toward drug use [26] and impulsivity in the development of drug use and its relation with the dopaminergic pathways [27]. In addition, some studies revealed the effect of impairments in dopaminergic pathways; especially an increase in dopamine, upon the occurrence of violence and uncontrolled behaviors [28].

The impulsivity and aggression are highly correlated with suicidal behavior [29]; therefore, more incidence of suicide attempt are expected among MA users. Severe neurotransmitter and brain impairments occur in MA abuse [30]. Thus, the consequences of such impairments (e.g. suicide attempt) are expected to be higher in MA users, compared to the opium users. No studies have directly compared the consequences of neurotransmitter disturbances resulting from MA and opium use. However, the above-mentioned points could be inferred from the literature review and individual investigations [31].

A study explored the prevalence of high-risk sexual behaviors and self-harm among the users of all types of drugs in Tehran. The greatest rate of high-risk sexual behaviors was reported by MA and cocaine users which reflects great risk-taking among them. The same study 
also reported the higher rates of self-harm in MA users, compared to opium users. This finding could explain the higher frequency of suicide attempt among female MA users, compared to female opium users [32].

\section{Conclusion}

Suicide attempt is much higher in females who use crystal MA, compared to female opium users. This could be a warning to prevent associated risks. Thus, it is necessary to establish preventive plans and manage to deliver emergency interventions, when required.

The main concern about the findings of current study is that the data were obtained by a cross-sectional survey on females' drug dependence in Tehran. Thus, the research was not initially designed in accordance with the achievements of the investigation. As a result, further research is suggested to be conducted with the same purpose, applying more appropriate research methods. Another limitation in the present study involves the lack of similar investigations, both in Iran and internationally, which made it impossible to directly compare the obtained results with prior data.

\section{Ethical Considerations}

\section{Compliance with ethical guidelines}

This article was part of a research project (Code: 801/93/10355/1) approved by the Ethics Committee of University of Social Welfare and Rehabilitation Sciences.

\section{Funding}

This study was funded by research deputy of University of Social Welfare and Rehabilitation Sciences.

\section{Authors contributions}

Developing the study concept, design and the definition of intellectual content: Ali Farhoudian, Omid Massah and Bahman Bahmani; Searched the literature: Omid Massah and Nastaran Rafiee; Conducting the study procedures and data collection: Elaheh Ahounbar, Seyed Hadi Mousavi and Mohsen Roshani; Data analysis: Omid Massah and Seyed Hadi Mousavi; Writing the manuscript: Omid Massah and Nastaran Rafiee; Editing and reviewing the manuscript and take responsibility for the integrity of the research as a whole from inception to published article: All authors.

\section{Conflict of interest}

The authors have no conflict of interest to declare.

\section{Acknowledgements}

The authors highly appreciate all the colleagues from different treatment or harm reduction centers who contributed to this research.

\section{References}

[1] United Nations Office on Drugs and Crime. World drug report 2017. Vienna, Austria: United Nations Office on Drugs and Crime; 2017.

[2] Roshanpajouh M. [House hold national survey on illicit drug use in Iran 2015 (Persian)]. Tehran: Welfare Organization of Iran; 2017.

[3] Amin-Esmaeili M, Rahimi-Movaghar A, Sharifi V, Hajebi A, Radgoodarzi R, Mojtabai R, et al. Epidemiology of illicit drug use disorders in Iran: prevalence, correlates, comorbidity and service utilization results from the Iranian mental health survey. Addiction. 2016; 111(10):1836-47. [DOI:10.1111/ add.13453] [PMID]

[4] Nikfarjam A, Shokoohi M, Shahesmaeili A, Haghdoost AA Baneshi MR, Haji MaghsoudiS, et al. National population size estimation of illicit drug users through the network scale-up method in 2013 in Iran. International Journal of Drug Policy. 2016; 31:147-52. [DOI:10.1016/j.drugpo.2016.01.013] [PMID]

[5] Massah O, Moradi A. The prevalence of methamphetamine dependence among Iranian women in methadone maintenance therapy in Tehran, Iran. Iranian Journal of Psychiatry. 2018; 13(1):10-4. [PMID] [PMCID]

[6] Darke S, Degenhardt L, Mattick R. Mortality amongst illicit drug users: Epidemiology, causes and intervention. Cambridge: Cambridge University Press; 2006. [DOI:10.1017/ CBO9780511543692] [PMCID]

[7] Carmel A, Ries R, West II, Bumgardner K, Roy-Byrne P. Suicide risk and associated demographic and clinical correlates among primary care patients with recent drug use. American Journal of Drug and Alcohol Abuse. 2016; 42(3):351-7. [DOI:1 0.3109/00952990.2015.1133634] [PMID] [PMCID]

[8] Icick R, Karsinti E, Lépine JP, Bloch V, Brousse G, Bellivier $\mathrm{F}$, et al. Serious suicide attempts in outpatients with multiple substance use disorders. Drug and Alcohol Dependence. 2017; 181:63-70. [DOI:10.1016/j.drugalcdep.2017.08.037] [PMID]

[9] Nock MK, Borges G, Bromet EJ, Alonso J, Angermeyer M, Beautrais A, et al. Cross-national prevalence and risk factors for suicidal ideation, plans and attempts. British Journal of Psychiatry. 2018; 192(2):98-105. [DOI:10.1192/bjp. bp.107.040113] [PMID] [PMCID]

[10] Darke S, Darke S, Kaye S, Darke S, Kaye S, McKetin R, et al. Major physical and psychological harms of metham- 
phetamine use. Drug and Alcohol Review. 2008; 27(3):253-62 [DOI:10.1080/09595230801923702] [PMID]

[11] Massah O, Shishehgar S, Karami Z. Methamphetamine dependence, psychological well-being, criminality and high risk sexual behaviors in female-only methadone services in Tehran and Karaj, Iran. Iranian Journal of Psychiatry and Behavioral Sciences. 2018:e61859. [DOI:10.5812/ijpbs.61859]

[12] Beck AT, Brown GK, Steer RA. Psychometric characteristics of the scale for suicide ideation with psychiatric outpatients. Behaviour Research and Therapy. 1997; 35(11):1039-46. [DOI:10.1016/S0005-7967(97)00073-9]

[13] Anisi J, Fathi-Ashtiani A, Soltani Nejad A, Amiri M. [Prevalence of suicidal ideation in soldiers and its associated factors (Persian)]. Journal of Military Medicine. 2006; 8(2):113-8.

[14] Mann JJ. Neurobiology of suicidal behaviour. Nature Reviews Neuroscience. 2003; 4(10):819-28. [DOI:10.1038/ nrn1220] [PMID]

[15] Miller L. Predicting relapse and recovery in alcoholism and addiction: Neuropsychology, personality, and cognitive style. Journal of Substance Abuse Treatment. 1991; 8(4):27791. [DOI:10.1016/0740-5472(91)90051-B]

[16] Fibiger Hc, Phillips Ag. Mesocorticolimbic dopamine systems and reward. Annals of the New York Academy of Sciences. 1988; 537(1):206-15. [PMID]

[17] Meredith CW, Jaffe C, Ang-Lee K, Saxon AJ. Implications of chronic methamphetamine use: A literature review. Harvard Review of Psychiatry. 2005; 13(3):141-54. [DOI:10.1080/10673220591003605] [PMID]

[18] Volkow ND, Chang L, Wang GJ, Fowler JS, Ding YS, Sedler M, et al. Low level of brain dopamine D2 receptors in methamphetamine abusers: Association with metabolism in the orbitofrontal cortex. American Journal of Psychiatry. 2001; 158(12):2015-21. [DOI:10.1176/appi.ajp.158.12.2015] [PMID]

[19] Volkow ND, Wang GJ, Fowler JS, Logan J, Gatley SJ, Wong C, et al. Reinforcing effects of psychostimulants in humans are associated with increases in brain dopamine and occupancy of D2 receptors. Journal of Pharmacology and Experimental Therapeutics. 1999; 291(1):409-15. [PMID]

[20] Ersche KD, Clark L, London M, Robbins TW, Sahakian BJ. Profile of executive and memory function associated with amphetamine and opiate dependence. Neuropsychopharmacology. 2005; 31(5):1036-47. [DOI:10.1038/sj.npp.1300889] [PMID] [PMCID]

[21] Keilp JG, Gorlyn M, Russell M, Oquendo MA, Burke AK, Harkavy-Friedman J, et al. Neuropsychological function and suicidal behavior: Attention control, memory and executive dysfunction in suicide attempt. Psychological Medicine. 2012; 43(3):539-51 [DOI:10.1017/S0033291712001419] [PMID] [PMCID]

[22] Majer JM, Beasley C, Jason LA. Suicide attempts and personal need for structure among ex-offenders. International Journal of Offender Therapy and Comparative Criminology. 2017; 61(3):334-46. [DOI:10.1177/0306624X15595981] [PMID] [PMCID]

[23] Conway KP, Kane RJ, Ball SA, Poling JC, Rounsaville BJ. Personality, substance of choice, and polysubstance involvement among substance dependent patients. Drug and Alcohol Dependence. 2003; 71(1):65-75. [DOI:10.1016/S03768716(03)00068-1]
[24] Conway KP, Swendsen JD, Rounsaville BJ, Merikangas KR. Personality, drug of choice, and comorbid psychopathology among substance abusers. Drug and Alcohol Dependence. 2002; 65(3):225-34. [DOI:10.1016/S0376-8716(01)00168-5]

[25] Sussman S, McCuller WJ, Dent CW. The associations of social self-control, personality disorders, and demographics with drug use among high-risk youth. Addictive Behaviors. 2003; 28(6):1159-66. [DOI:10.1016/S0306-4603(02)00222-8]

[26] Massah O, HoseinSabet F, Doostian Y, A'zami Y, Farhoudian $\mathrm{A}$. The role of sensation-seeking and coping strategies in predicting addiction potential among students. Practice in Clinical Psychology. 2014; 2(3):173-80

[27] Dawe S, Loxton NJ. The role of impulsivity in the development of substance use and eating disorders. Neuroscience \& Biobehavioral Reviews. 2004; 28(3):343-51. [DOI:10.1016/j. neubiorev.2004.03.007] [PMID]

[28] Ryding E, Lindström M, Träskman-Bendz L. The role of dopamine and serotonin in suicidal behaviour and aggression. In: Di Giovann G, Di Matteo V, Esposito E, editors. Progress in Brain Research. Amsterdam: Elsevier; 2008. [DOI:10.1016/ S0079-6123(08)00915-1]

[29] Gvion Y, Apter A. Aggression, impulsivity, and suicide behavior: A review of the literature. Archives of Suicide Research. 2011; 15(2):93-112. [DOI:10.1080/13811118.2011.56526 5] [PMID]

[30] Thomas E. Nordahl, Ruth Salo, Martin Leamon. Neuropsychological effects of chronic methamphetamine use on neurotransmitters and cognition: A review. The Journal of Neuropsychiatry and Clinical Neurosciences. 2003; 15(3):317-25. [DOI:10.1176/jnp.15.3.317] [PMID]

[31] Zaitsu K, Hayashi Y, Kusano M, Tsuchihashi H, Ishii A Application of metabolomics to toxicology of drugs of abuse: A mini review of metabolomics approach to acute and chronic toxicity studies. Drug Metabolism and Pharmacokinetics. 2016; 31(1):21-6. [DOI:10.1016/j.dmpk.2015.10.002] [PMID]

[32] Mirsoleimani L, Sanaee zaker B, Vaziri S. The comparison of sexual behavior high risk sexual behaviour and self-harm behaviour in stimulants/narcotic substance abuse. Research on Addiction. 2009; 3(9):155-72. 
This Page Intentionally Left Blank 